\title{
BMJ Open Understanding attitudes and norms related to sexual and gender-based violence among youth in Jordan: an egocentric social network study protocol
}

\author{
Jewel Gausman (D) , Eman Abu Sabbah, ${ }^{2}$ Areej Othman, ${ }^{2}$ Iqbal Lutfi Hamad, ${ }^{3}$ \\ Maysoon Dabobe, ${ }^{3}$ Ana Langer ${ }^{1}$
}

To cite: Gausman J, Abu Sabbah E, Othman A, et al. Understanding attitudes and norms related to sexual and gender-based violence among youth in Jordan: an egocentric social network study protocol. BMJ Open 2021;11:e047615. doi:10.1136/ bmjopen-2020-047615

- Prepublication history and additional supplemental material for this paper are available online. To view these files, please visit the journal online (http://dx.doi.org/10.1136/ bmjopen-2020-047615).

Received 08 December 2020 Accepted 05 November 2021

Check for updates

(C) Author(s) (or their employer(s)) 2021. Re-use permitted under CC BY-NC. No commercial re-use. See rights and permissions. Published by BMJ.

${ }^{1}$ Women \& Health Initiative; Department of Global Health and Population, Harvard T.H. Chan School of Public Health, Harvard University, Boston,

Massachusetts, USA

${ }^{2}$ Department of Maternal and Child Health Nursing, School of Nursing; The University of Jordan, Amman, Jordan

${ }^{3}$ Jordanian Hashemite Fund for Human Development, Amman, Jordan

Correspondence to Dr Jewel Gausman; jmg923@mail.harvard.edu

\section{ABSTRACT}

Introduction Sexual and gender-based violence (SGBV) is a major public health concern in Jordan, especially among youth. Social acceptance of SGBV is alarmingly high, including among youth. Refugee populations may be at particular risk given limited social support and access to health services combined with increased social and economic pressure and vulnerability. Further research is needed to understand how norms are embodied and reproduced at individual, interpersonal and community levels through relationships between partners, families, peers and community leaders. This study seeks to provide data on attitudes and norms in communities and across youth social networks in order to support gender transformative approaches that seek to change harmful social norms that perpetuate acceptance of SGBV.

Methods and analysis This study will collect egocentric data from 960 youth in Jordan (480 men and 480 women) aged between 18 years and 24 years. Individuals will be asked about their perceptions of norms relating to SGBV in their community as well as their perceptions of the attitudes held by up to 15 individuals within their social network. Data will also be collected on the social, economic and demographic variables, refugee status, experience of depression and anxiety, and social support. We will use multilevel analysis to examine individual and group-level associations. We will also assess other network attributes, such as homophily, the role of social engagement, social learning and social support in the transmission of norms and attitudes.

Ethics and dissemination Ethical approval was obtained from the Institutional Review Boards of the Harvard T.H. Chan School of Public Health and the University of Jordan. Rigorous ethical protections will be followed with regard to confidentiality and respondent safety. We intend to publish peer-reviewed papers of our findings in addition to a variety of tools and resources targeting diverse audiences, including policy and technical briefs.

\section{INTRODUCTION}

Reducing the prevalence of sexual and gender-based violence (SGBV) in Jordan is an important public health priority. ${ }^{1}$ SGBV is considered a human rights violation that is usually directed against individuals
Strengths and limitations of this study

- Study follows an egocentric social network approach designed to collect information on attitudes related to sexual and gender-based violence (SGBV) across diverse networks.

- Study collects data on injunctive norms related to SGBV andincludes a large sample of male and female refugee youth from a diverse and disadvantaged urban community.

- Participants, especially unmarried women, may be hesitant to disclose sensitive information about romantic relationships given the conservative setting.

- Data will be collected from one geographic area, thus limiting generalisability of results.

because of their gender. Both women and men experience SGBV; however, according to existing figures, the majority of victims are women and girls. Results from the 2017 Jordan Population and Family Health Survey (JPFHS) indicate that $26 \%$ of women have experienced some form of physical, sexual or emotional violence since the age of 15 years. ${ }^{2}$ Physical, emotional, psychological and verbal abuse, controlling behaviour, and intimidation are commonly perpetrated against women by their fathers, family members, intimate partners and other male community members. Furthermore, controlling behaviour displayed by husbands is relatively common, with $66 \%$ of ever-married women reporting that their husbands become angry if they speak with other men, and 32\% insist on knowing their whereabouts at all times. ${ }^{2}$ Youth are often particularly vulnerable to SGBV because of gender discrimination, rigid social expectations, increasing economic hardship and poverty and a lack of protective institutions. Recent changes in community dynamics resulting from refugee flows have also caused youth to become increasingly 
vulnerable to SGBV. ${ }^{34}$ While the prevalence of SGBV in Jordan has declined overall in recent years, in some disadvantaged communities, there are fears that sexual assault, rape, child marriage and honour killing are becoming increasingly common. According to the Jordanian government's 2014 submission to the UN Committee on the Rights of the Child, 50 cases of honour killing were reported between 2000 and 2010, and of those cases, $12 \%$ of victims were under 18 years and $56 \%$ were between 18 years and 28 years. ${ }^{5}$

Jordan hosts a large number of refugees from across the Middle East. The majority of refugees in Jordan live in host communities rather than in refugee camps. The influx of Syrian refugees over the last decade has placed considerable strain on many communities. Of the 1.2 million Syrian refugees living in Jordan, ${ }^{6}$ only $16 \%$ reside in official camps. ${ }^{7-9}$ Additionally, two million Palestinian and 500000 Iraqi refugees live in Jordan; the majority of whom live in Amman. ${ }^{1011}$ Prevalence estimates of SGBV among refugee populations in Jordan remain limited-especially for the majority of refugees who live outside of camps; however, a qualitative study found that in camps, women aged 12-18 years are thought to be the most common targets of domestic and sexual violence, and many youth have reported an increase in SGBV since coming to Jordan. ${ }^{12}$ Among Palestinian refugees under 20 years of age, one study found that among female respondents, $83 \%$ have experienced controlling behaviour, while $63 \%$ and $40 \%$ reported economic and emotional violence, respectively. ${ }^{13}$

The prevalence of child marriage in Jordan is a contentious issue; however, data indicate that it is increasingespecially among Syrians. In 2013, $13 \%$ of all marriages registered in Jordan included a woman under the age of 18 years, with $12 \%$ among Jordanians, $18 \%$ among Palestinians, 25\% among Syrians and 4\% among Iraqis. ${ }^{14-17}$ Data from 2016, however, indicate that $34 \%$ of all Syrian marriages in Jordan involved a minor. ${ }^{14} 18$ Research in Syrian refugee camps found that girls report that the most common age for girls to marry is 15 years, with a range from 13 years to 20 years. ${ }^{19}$ Across Jordan, the 2012 JPFHS suggests that poorer and less educated women were more likely to marry before the age of 18 years than richer and better educated women. ${ }^{20}$

In Jordan, patterns of abuse are first established, normalised and entrenched within the home. ${ }^{21}$ The 2017 JPFHS reports that among women reporting having experienced violence since the age of 15 years, $13.9 \%$ said that it was perpetrated by their brother, $11.9 \%$ said that it was perpetrated by their father and 9.1 said that it was perpetrated by their mother, while $81 \%$ of children experience physical violence at home between the ages of 2 years and 14 years. ${ }^{2}$ Jordanian and Syrian women have described how the cycle of abuse begins during childhood by seeing violence committed against their mothers, but also by their fathers teaching sons to commit violence against women and female family members, such as through the use of violence to force women into early marriages. ${ }^{17} 22$
As youth begin to develop their own social networks, childhood beliefs are reaffirmed and challenged by new social interactions. In Jordan, the widespread acceptance of SGBV appears to reinforce such attitudes in the younger generations. More younger women appear to tolerate SGBV than older women. The 2017 JPFHS reports that $63 \%$ of women aged $15-19$ years agree that a man is justified in hitting his wife for at least one reason, while between $45 \%$ and $47 \%$ of older women agree; on average, Syrian women (63\%) are more likely to agree with at least one reason for wife beating than Jordanians $(45 \%) .^{2}$ Among men, on average, $69 \%$ of men agree that hitting their wife is justifiable for at least one reason. ${ }^{2}$ Some research works among Syrian men in Jordanian camps indicate that a majority of men believe that wife beating is acceptable. ${ }^{16} \mathrm{~A}$ study of 856 adolescents aged 14-16 years from across Jordan found that $40 \%$ of boys and $20 \%$ of girls believe that killing a daughter, sister or wife for dishonouring the family is justifiable. ${ }^{23}$ Perceived community norms can also be powerful in influencing beliefs and behaviours. One study found that many individuals feel forced into marrying their daughters early due to social pressure, ${ }^{14}$ while others report that child marriage preserves a family's honour in the eyes of the community. ${ }^{1424}$ Young Syrian women also report that girls who marry early obtain more respect from the community regardless of their age. ${ }^{25}$

Social norms are often defined in terms of descriptive norms and injunctive norms. Descriptive norms are how individuals perceive others in their social group to behave, while injunctive norms are an individual's perceptions of what others in their social group view as appropriate or expected behaviour. ${ }^{26}$ Individuals may engage in a specific behaviour because they believe that most other people in their social group also engage in that specific behaviour, or they may behave in a certain way because they believe that others expect a certain behaviour from them. Previous research has found that in the case of SGBV norms may be distinct from individual beliefs or attitudes. ${ }^{27}$ The relationship between individual beliefs, norms and behavioural outcomes is complex; individuals may feel pressure to conform to their perceptions of social expectations or what they believe to be a common behaviour, even if they personally disagree. ${ }^{28}$ Furthermore, individual's perceptions of injunctive or descriptive norms may not in fact represent the dominant behaviours or beliefs among individuals within their social groups.

Understanding attitudes and norms related to SGBV is particularly important for intervention design both in terms of prevention and support for survivors. Interventions designed to change norms focus on the interconnections between individuals within social groups to target norms directly or indirectly by shifting attitudes, beliefs or behaviours to shift norms. ${ }^{28}$ Previous interventions based on network theory have sought to shift norms related to SGBV in order to develop a critical mass of individuals within a community to challenge the underlying drivers of SGBV. ${ }^{29}$ Such interventions may promote both 
prevention and support for survivors, in that the reactions of people within survivor's social networks may not only serve to reinforce attitudes that shape norms, but also may directly influence a woman's safety and well-being if such people reject the norms that sustain SGBV as a common practice. ${ }^{12} 3031$ Often women and girls are most likely to disclose abuse to family members, neighbours and peers before disclosing such information to service providers or other authority figures. In Jordan, the majority of women never seek help or tell anyone about abuse; however, among women who do seek help, many report going to members of their own family or their husband's family for help, while very few women reported going to formal institutions, such as medical personnel or police. ${ }^{2}$

The research questions and approach described in this proposal contribute to an important new direction in research on SGBV prevention and respond directly to calls in the literature to examine SGBV as a social construct embedded within a broader ecological system, rather than an individual-level phenomenon. ${ }^{30}$ Social network research has proliferated over the last two decades across a wide variety of health domains (including infectious disease, cancer, maternal health, sexual behaviour and mental health, among others ${ }^{32}$; however, few studies have focused on the role of social networks in influencing attitudes or behaviours related to gender equity or SGBV. A network study conducted in Honduras found that attitudes accepting of intimate partner violence (IPV) were clustered among social contacts, while as a norm, acceptance of IPV was more likely to be accepted by individuals who had fewer social ties within the community. ${ }^{33}$ Given the limited understanding to date of how network relationships contribute to attitudes in relation to SGBV, this study and its results could have a significant impact on how SGBV is studied, understood and intervened on in future research and programmes. Further research is needed to understand how norms are embodied and reproduced at individual, interpersonal and community levels through relationships between families, peers, partners and communities. ${ }^{30} 34$ The findings of our research will contribute to gender transformative approaches that seek to promote change across the social ecology.

Our study aims to understand how attitudes and behaviours related to SGBV and gender inequity are developed and transmitted across youth social networks in Jordan at different levels of the social ecological model. Our ultimate goal is to recommend evidence-based network approaches to create transformative change at the community level.

The specific objectives for this research study are as follows:

1. Examine the prevalence of SGBV in the study population as it relates to key social, demographic and healthrelated variables.

2. Describe how attributes of youth social networks are associated with normative beliefs related to SGBV through hypothesised mechanisms of influence.
3. Explore how different social contexts may be associated with attitudes and normative beliefs related to SGBV.

\section{METHODS AND ANALYSIS \\ Study design}

This study will follow a cross-sectional, egocentric social network design in which individuals provide information on themselves and others within their social networks (referred to as alters) ${ }^{35}$ Egocentric studies are widely used in social network research to examine attitudes, relationships and mechanisms through which networks influence individual attitudes and behaviours. ${ }^{36}{ }^{37}$ Following this type of study design, individuals will be asked about their own personal beliefs and attitudes and perceptions of their community, while being asked about their perceptions of their alters; thus their alters will never be contacted or participate in any study activities.

\section{Study setting}

The study will be conducted in East Amman, which has become more conservative, disadvantaged and ethnically diverse as a result of the refugee crisis. Thirty per cent of Jordan's Syrian refugees live in East Amman ${ }^{9}$ as well as large numbers of Palestinians, Iraqi, Yemeni and Sudanese refugees. ${ }^{10}$ East Amman is an ideal site for the research because of its high population density, large youth population and ethnic diversity.

\section{Study population and recruitment}

The study population will include men and women aged between 18 years and 24 years. ${ }^{38}$ Eligibility criteria are based on willingness to participate and age only (respondent must consent and be aged between 18 years and 24 years). A convenience sample of 960 participants (480 men and 480 women) will be recruited via four community centres located in East Amman.

The community centres where the study will take place house a wide variety of activities on issues relevant to community development, including economic livelihoods programmes, civil society programmes, community leadership activities, etc. Several of the programmes offered at the centre specifically target youth. The centres serve as a community hub and resource centre and are widely accessed by all demographic groups represented in the community; programmes do not generally target individuals of a specific national origin.

Given the diversity present within the study setting, we expect our sampling approach to yield a diverse sample of participants from a variety of backgrounds, including refugees and members of the host community; however, as conducting comparisons by national origin or refugee status is not a specific aim of the study, we do not specify recruitment parameters based on national origin.

Study staff will be present at the community centres during the times of day when they are most frequented by youth. Study staff will approach potential participants with a standard screening questionnaire. If a participant 
meets the eligibility criteria, s/he will be invited to participate in the study using a standard study script. Men and women will be recruited from separate sites as a protection measure to safeguard confidentiality by reducing the risk that we recruit men and women who are married or in a romantic relationship or those who are members of the same family from the same site.

\section{Sample size}

Standard population sampling methods are recommended for social network studies. ${ }^{9}$ We estimated the sample size required separately for men and women using the formula for a single proportion $\left(n=z^{2} \times p(1-p) / r^{2}\right)$, where $\mathrm{z}$ is $1.96, \mathrm{p}$ is the proportion of the population who reject SGBV, estimated at 50\%, as the real value in the population is unknown, and $\mathrm{r}$ is the margin of error equal to $5 \%$, which resulted in an estimated sample required of 384 participants. To account for non-response and missing data, we added an additional $25 \%$ to the sample, resulting in a sample required of 480 participants in each group. The proposed study population is robust compared with similar network studies that focus on attitudes within communities. ${ }^{37}$ Furthermore, we will ask each participant to name up to 18 alters and collect data on each of those alters; however, the number of alters named by a given participant will vary based on their own social network. Past research suggests that collecting data on between 15 alters and 20 alters is sufficient for producing reliable and valid measures within an egocentric network. ${ }^{39-41}$

\section{Primary outcomes}

Our definition of SGBV is 'any act of gender-based violence that results in, or is likely to result in, physical, sexual, or psychological harm or suffering, ${ }^{42}$ We operationalise this definition to include forms of violence that are of specific importance to the study setting, including rape; sexual harassment; emotional, psychological or physical abuse; controlling behaviours; differential access to resources; child marriage (marriage under the age of 18 years); and honour killing. ${ }^{43}$ Specific outcomes of interest correspond to our study objectives and include (1) whether a respondent has experienced IPV, (2) perpetration of IPV and (3) endorsement of norms related to SGBV. For each of our outcome measures, we will rely on careful adaptations of existing instruments that have been validated either in Jordan or elsewhere in the region or with similar populations.

To measure psychological, physical and sexual violence and controlling behaviour from an intimate partner, we will use a version of the WHO's Domestic Violence Module that has previously been adapted, translated, tested and validated in Jordan. ${ }^{1}$ As in previous studies, this module will be self-administered with a data collector present in the room. ${ }^{1}$ Items included in the questionnaire refer to specific representations of violence that are locally relevant that fall into each of the defined categories and are detailed elsewhere. ${ }^{1}$ For each item in the questionnaire, women will be asked if they have experienced within the last year or prior to the last year as well as a question about the general frequency.

To measure men's perpetration of violence, we have incorporated questions from the UN Multi-country Cross-sectional Study on Men and Violence in Asia and the Pacific, coordinated and funded by Partners for Prevention, which is a UN Development Programme, UN Population Fund, UN Women and UN Volunteers regional joint programme for prevention of genderbased violence in Asia and the Pacific. ${ }^{44}$ Questions focus on the same domains of violence included in the women's questionnaire (physhological, physical and sexual violence and controlling behaviour) and also ask about the frequency.

While no single, gold standard tool exists to measure attitudes and norms related to SGBV, we have adapted several previously validated tools from the published literature. We will seek to measure attitudes and norms related to SGBV from multiple dimensions, including (1) the respondent's attitudes, (2) injunctive norms and (2) and the perceived attitudes of alters.

To collect data on both individual's own attitudes and norms within their community, we draw on several existing tools. We adapted the Social Norms and Beliefs about GBV Scale, which was previously tested and validated in Somalia and Sudan, to the Jordanian context to collect data on an individual's perceptions of common behaviours and social expectations related to different domains of SGBV ${ }^{45}$ While the tool was developed in a different context, it was developed using data from two diverse populations, and is thought to be generalisable to other low-resource and fragile settings. ${ }^{45}$ To ensure adequate content validity and local relevance of the items included in the tool, we conducted an extensive review of existing academic literature and programmatic reports from Jordan to identify other normative measures and consulted with local and international experts. Based on these inputs, we added specific questions derived from existing tools important to the Jordanian context on honour killing, child marriage, bullying and harassment. ${ }^{2346}$ The items included in our tool focus on injunctive norms given the availability of existing instruments, as developing a new measure focused on descriptive norms was beyond the scope of this study. To measure the strength of injunctive norms, we ask the participant to indicate whether they think that all, most, half, few or none of the people in their community would agree with each statement, and then we ask them to rate their own personal beliefs related to each statement on a scale of 1 (strongly disagree) to 4 (strongly agree). While items relate to different types of SGBV, the Scale is meant to capture the construct in aggregate using culturally relevant examples, rather than to be disaggregated by norms measuring specific types of violence. Specific items from the scale are included in online supplemental file 1 . We will examine the psychometric properties of the adapted scale, including construct validity through factor analysis 
and internal consistency reliability by calculating Cronbach's alpha on the final sample prior to performing our analysis.

\section{Measurement of social networks}

To collect data on respondents' social networks, we use multiple name generators which consist of questions designed to collect data on individual's social ties. ${ }^{47}$ Alters will be identified through a series of prompts that ask the respondent to consider different types of social relationships, including close personal relationships and acquaintances from community groups, school or work. ${ }^{48}$ As we hypothesise that social support (defined as instrumental, emotional, material and informational resource exchanges) is important to the formation of attitudes related to SGBV, we selected the name generators based on these underlying social processes. ${ }^{39} 48$ For example, participants are asked who they discuss important matters with, who they enjoy socialising with, who they go to for advice and who they would borrow a basic household item from. Furthermore, the name generators were designed to elicit both deep personal contacts as well as transitory, but influential, encounters in one's neighbourhood or in community or religious groups. ${ }^{39}$ Relationship questions will focus on the type of relationship (father, sibling, close friend, etc), closeness and duration of the relationship, frequency of contact, and other relationship attributes, which may influence the importance. Basic demographic questions about alters' will be asked, as well a subset of the norms questions included in study to focus on specific items, as asking all of the questions related to the full attitude scale would not be practical and would be overly burdensome to participants. Last, participants will be asked to characterise the relationship between their alters, thus enabling us to examine relationships between individuals, without linking directly back to the respondent.

\section{Other covariates}

We will also collect data on other social and demographic variables, including wealth (through an asset-based index), marital and health status, and refugee status. Variables on social support and capital will be collected by asking about perceptions of community trust and sense of belonging from the Short Social Capital Assessment Tool $^{49} 50$ and the widely used Multidimensional Perceived Social Support Scale, which has previously been translated and used with adolescent Arabic-speaking immigrants in the USA and a community sample in Lebanon. ${ }^{51-53}$ Given the important link between SGBV and mental health, depression and anxiety will be assessed using the Patient Health Questionnaire-4 (PHQ-4), which is a widely used, brief screening tool. ${ }^{54}$ Attitudes and norms related to gender equity will be collected using questions adapted from a scale tested and validated in Egypt $t^{55}$ and items from the Gender-Equitable Men Scale that has been validated in several countries globally. ${ }^{56}$

\section{Study procedures}

All tools were developed in English. Two bilingual individuals translated the study tools into Arabic from English. All tools were then back translated to English. Furthermore, two additional individuals, not involved in translation, carefully reviewed the English and Arabic versions of the tools prior to finalisation. Data collection is expected to begin in January 2021 and be completed by June 2021, though uncertainties related to the ongoing COVID-19 pandemic may result in a longer study time frame. Data analysis is expected to take place between June 2021 and November 2021.

All tools will be pretested prior to commencement of data collection. Cognitive interviewing will be conducted with five individuals to ensure comprehension. Pilot testing will be carried out with 20 individuals to look for lack of understanding, implementation challenges and patterns in missing responses. We expect that the survey will take between 1 hour and 1.5 hours to complete and we will verify the accuracy of that timing estimate during pretesting.

Data will be collected through individual surveys administered by trained, local data collectors. Data collectors were trained during a 3-day training, with 1 day dedicated to each of the following: (1) ethics and study overview, (2) orientation to the tool and tablets and (3) interactive practice and feedback. Data collectors will be of the same sex and approximate age as study participants and will be recruited from among the staff at the community centres.

Either immediately following recruitment or another prearranged convenient time, participants will be interviewed in private rooms at the community centre. Informed consent will be administered immediately prior to conducting the interview. Transportation reimbursement will be provided as is standard in conducting similar researches in those institutions.

Tablets will be used to record responses and to facilitate data entry and management. The portion of the survey collecting demographic, social, attitudinal and normative data will be administered verbally by the data collector. Questions on mental health status and experience with SGBV will be self-administered on the tablet by the respondent so as to further safeguard against any breaches in confidentiality and make respondents more comfortable disclosing sensitive information. The data collector will be available throughout should the participant have any clarifying questions, experience any distress or want to terminate the interview.

\section{Analysis}

Both graphical and statistical approaches will be used to analyse the data generated. All data analysis will be completed using the statistical program $\mathrm{R}^{57}$

For objective 1, we will examine the distribution of SGBV across various social and demographic covariates using descriptive statistics. Furthermore, we will explore how prevalence and perpetration of SGBV varies according to structural attributes of the network, and key 
outcomes of interest. As data are hierarchical and violate standard statistical assumptions, multilevel regression analysis will be used to examine associations between variables of interest and key outcomes in relation to network attributes.

For objective 2, we will examine how the hypothesised mechanisms that generate and transmit attitudes operate within the network. In particular, we will examine network attributes, such as homophily, clustering, density and proximity. Threshold models will be used to examine critical mass, that is, whether individuals engage in a behaviour based on the proportion of alters who espouse the given behaviour. ${ }^{58}$ Data collected on alters will enable us to operationalise hypothesised mechanisms in our analysis, such as examining social learning by examining the closeness of an individual's relationship with their alter, ${ }^{59}$ social engagement through an individual's group participation $^{59}$ and social support by analysing the flow of resources between individuals within a network.

For objective 3, we will examine the relative importance of difference social contexts on SGBV and gender-related attitudes. Multilevel regression models will be used to decompose the variance structure at different levels of the ecological model (families, schools, peer groups, etc) with regard to outcomes of interest. Individual and group-level variables will be considered, and cross-level interactions will be examined to explore how individual characteristics interact with different layers of social context in relation to SGBV and gender.

\section{Public and patient involvement}

No patients were involved in this study. The research and outcome measures were developed through formative research with youth living in Jordan on concerns related to their reproductive health. We will disseminate aggregate results from our study to local stakeholders where the research took place to better inform local programming for SGBV prevention and response.

\section{Ethics and dissemination}

\section{Ethical considerations}

We will undertake extensive measures to ensure that our study meets the highest ethical standards for research with human subjects, as well as specific requirements necessary to ensure the safety of study staff and respondents given the sensitivity of the topic. We will follow internationally recognised ethical standards for conducting research on SGBV, as well as research within refugee settings. ${ }^{6061}$ Our study's focus on social networks in the domain of SGBV introduces some unique ethical challenges that we will fully address during the development of the research protocol. However, there are several specific ethical considerations worth highlighting.

Ethical approval has been obtained through Institutional Review Boards of the Harvard T.H. Chan School of Public Health and the University of Jordan. Data collectors undergo rigorous ethical training prior to conducting research. We will ensure that individuals choose to participate in the study on a voluntary basis, with no undue coercion. All participants will provide informed consent before participating in the study.

Additionally, while youth (typically defined between the ages of 15 years and 24 years) ${ }^{38} 62$ are of specific interest in this study, we have made the deliberate decision to only include youth who have reached the age of majority (18 years and above). We made the decision to only include participants aged 18 and above for several reasons; first, we wanted ensure that respondents are able to give full informed consent, and second, we wanted to ensure confidentiality and reduce risk to participants by avoiding the need for parental permission as we will ask about family violence.

In social network research, there are additional ethical considerations related to the rights of alters named by the respondent. Even though we will ask respondents' personal information about the alters (eg, if the alter was married before reaching the age of majority), our study will meet the conditions of the Common Rule waiver of consent as no personally identifiable information will be collected about the alters and there will be no adverse effects on the alters' rights and welfare resulting from the study. ${ }^{36}$ Respondents will be asked to keep their participation in the study confidential. All data will be anonymised at the time of entry. No names or other personally identifiable information will be collected. During the name generation process, exact names will not be requested. Rather, participants will be asked to refer to alters by first names, initials or in any way they wish; once the interview is complete and uploaded, an algorithm will be applied to generate anonymous codes for each alter and the name given by the respondent will be deleted.

We will undertake several steps to ensure the safety of the respondents and the research team. Respondents will not be recruited from their home and we will not advertise the purpose of the study to avoid any backlash related to participation. All interviews will be conducted at community centres to ensure the safety of both the respondent and the data collectors. There are private spaces within these centres where respondents will not be seen or heard. A wide variety of individuals come to the community centres where the research will be conducted, so one's presence at the centre will not be associated with this specific study. While data collection will occur indoors, efforts to reduce the risk of COVID-19 will be implemented in accordance with local and international guidelines and recommendations. Both respondents and data collectors will be given appropriate personal protective equipment, including hand sanitizers and masks to protect against COVID-19, and only the data collector and respondent will be present in the room at the time of the survey, while maintaining a safe distance.

We will work with local health centres and women's organisations focused on SGBV in advance of data collection activities to establish a relationship so that we may seamlessly provide referrals should participants want additional information or request help. At the culmination of 
each interview, all participants will be given a card with information about local public health services.

Respondents will be asked about whether they have experienced violence, which may be distressing. Data collectors will be trained in appropriate body language and respectful interactions so as to be sensitive to the needs of the respondent. Furthermore, data collectors will be trained on identifying if/when respondents appear to be in distress and an action plan will be developed to ensure safety of all participants.

\section{Dissemination}

The findings of this study will be used to improve SGBV prevention efforts in Jordan, within the Middle East, and globally by providing innovative data, analysis, recommendations and materials that are directly relevant to policymakers, programme managers and other stakeholders. Through our research activities, we will focus directly on generating and documenting specific lessons learnt, as well as research and programmatic recommendations that are directly translatable to policy and practice. While our ultimate objective is to contribute to a reduction in SGBV in Jordan, our hope is that our research will inform youth-oriented SGBV programmes across the region and the globe.

In addition to peer-reviewed publications highlighting our findings, we intend to (1) generate a variety of tools and resources targeting different stakeholders and audiences, such as policy and technical briefs, (2) hold targeted one-on-one dissemination meetings with local organisations, donors and policy-makers and (3) use webbased platforms to engage an international audience in trainings and discussion of the research methodology and results.

Contributors JG wrote the first draft and conceptualised the study. EAS, AO and AL contributed to tool development. EAS, AO, ILH, MD and AL contributed to study methodology and critical review of the manuscript.

Funding This work was supported by the Sexual Violence Research Initiative World Bank Group Development Marketplace for Innovation on Gender-Based Violence Prevention and Response.

Competing interests None declared.

Patient consent for publication Not applicable.

Provenance and peer review Not commissioned; externally peer reviewed.

Supplemental material This content has been supplied by the author(s). It has not been vetted by BMJ Publishing Group Limited (BMJ) and may not have been peer-reviewed. Any opinions or recommendations discussed are solely those of the author(s) and are not endorsed by BMJ. BMJ disclaims all liability and responsibility arising from any reliance placed on the content. Where the content includes any translated material, BMJ does not warrant the accuracy and reliability of the translations (including but not limited to local regulations, clinical guidelines, terminology, drug names and drug dosages), and is not responsible for any error and/or omissions arising from translation and adaptation or otherwise.

Open access This is an open access article distributed in accordance with the Creative Commons Attribution Non Commercial (CC BY-NC 4.0) license, which permits others to distribute, remix, adapt, build upon this work non-commercially, and license their derivative works on different terms, provided the original work is properly cited, appropriate credit is given, any changes made indicated, and the use is non-commercial. See: http://creativecommons.org/licenses/by-nc/4.0/.
ORCID iD

Jewel Gausman http://orcid.org/0000-0002-9880-2591

\section{REFERENCES}

1 Clark CJ, Bloom DE, Hill AG, et al. Prevalence estimate of intimate partner violence in Jordan. East Mediterr Health J 2009;15:880-9.

2 Department of statistics (DOS) and ICF. Jordan population and family and health survey 2017-18. Amman, Jordan, and Rockville, Maryland, USA: dos and ICF, 2019.

3 Jordan Communication Advocacy and Policy Activity. Family planning among Syrian refugees in Jordan: March 2016, 2016.

4 VAF Assessment Team. Vulnerability assessment framework baseline survey. Amman, Jordan: UNHCR, 2015.

5 Al Gharaibeh FM. Debating the role of custom, religion and law in 'honour' crimes: implications for social work. Ethics Soc Welf 2016;10:122-39.

6 Department of Statistics [Jordan]. 2015 national census report, 2016.

7 Doocy S, Lyles E, Roberton T, et al. Prevalence and care-seeking for chronic diseases among Syrian refugees in Jordan. BMC Public Health 2015;15:1097.

8 Achilli L. Syrian refugees in Jordan: a reality check, 2015. Available: https://cadmus.eui.eu/handle/1814/34904

9 UNHCR. Syrian refugees living outside of camps in Jordan: home visit data findings, 2013. Available: https://reliefweb.int/sites/ reliefweb.int/files/resources/HVreport_09MarCS6_smallsize.pdf

10 UNFPA. Iraqis in Jordan: their number and characteristics. Amman, Jordan: UNFPA, 2007.

11 UNRWA. Where we work. Available: https://www.unrwa.org/wherewe-work/jordan

12 UNICEF. Shattered lives: challenges and priorities for Syrian children and women in Jordan, 2013. Available: https://reliefweb.int/report/ jordan/shattered-lives-challenges-and-priorities-syrian-children-andwomen-jordan

13 Al-Modallal H, Abu Zayed I, Abujilban S, et al. Prevalence of intimate partner violence among women visiting health care centers in Palestine refugee camps in Jordan. Health Care Women Int 2015;36:137-48.

14 Unicef. A study on early marriage in Jordan 2014, 2014. Available: https://reliefweb.int/report/jordan/study-early-marriage-jordan2014\#: :text=Among\%20Syrian\%20refugees\%20living\%20in, the \%20first \%20quarter\%20of\%202014.\&text=Jordanian\%20law\% 20 puts $\% 20$ the\%20legal,girls\%20and\%20boys\%20at\%2018.

15 Samari G. Syrian refugee women's health in Lebanon, Turkey, and Jordan and recommendations for improved practice. World Med Health Policy 2017;9:255-74.

16 Jordan communication advocacy and policy activity. Family planning among Syrian refugees living in Jordan, 2016. Available: https:// jordankmportal.com/resources/family-planning-among-syrianrefugees-in-jordan

17 UNFPA regional Syria response hub. Women and girls in safe spaces: a guidance note based on lessons learned from the Syrian crisis. London: UNFPA, 2015.

18 Higher Population Council. ندرالا يف تارصاقلا جاوز ةسارد Amman, Jordan: Higher Population Council, 2017.

19 Krause S, Williams H, Onyango MA, et al. Reproductive health services for Syrian refugees in Zaatri cAMP and Irbid City, Hashemite Kingdom of Jordan: an evaluation of the minimum initial services package. Confl Health 2015;9:S4.

20 Clark CJ, Spencer RA, Khalaf IA, et al. The influence of family violence and child marriage on unmet need for family planning in Jordan. J Fam Plann Reprod Health Care 2017;43:105-12.

21 Sabbah EA, Chang Y-P, Campbell-Heider N. Understanding intimate partner violence in Jordan: application of the ecological model. Perspect Psychiatr Care 2017;53:156-63.

22 Safadi R, Swigart V, Hamdan-Mansour AM, et al. An ethnographicfeminist study of Jordanian women's experiences of domestic violence and process of resolution. Health Care Women Int 2013;34:775-94.

23 Eisner M, Ghuneim L. Honor killing attitudes amongst adolescents in Amman, Jordan. Aggress Behav 2013;39:405-17.

24 Spencer D. To protect her honour. child marriage in emergencies-the fatal confusion between protecting girls and sexual violence, 2015. Available: https://insights.careinternational.org.uk/publications/ to-protect-her-honour-child-marriage-in-emergencies-the-fatalconfusion-between-protecting-girls-and-sexual-violence

25 Women UN. Gender-Based violence and child protection among Syrian refugees in Jordan, with a focus on early marriage. Amman, Jordan: UN Women, 2013. 
26 Cialdini RB, Kallgren CA, Reno RR. A focus theory of normative conduct: a theoretical refinement and reevaluation of the role of norms in human behavior. Adv Exp Soc Psychol 1991;24:201-34.

27 Banyard V, Edwards K, Rizzo A. "What would the neighbors do?" Measuring sexual and domestic violence prevention social norms among youth and adults. J Community Psychol 2019;47:1817-33.

28 Lilleston PS, Goldmann L, Verma RK, et al. Understanding social norms and violence in childhood: theoretical underpinnings and strategies for intervention. Psychol Health Med 2017;22:122-34.

29 Abramsky T, Devries K, Kiss L, et al. Findings from the Sasa! study: a cluster randomized controlled trial to assess the impact of a community mobilization intervention to prevent violence against women and reduce HIV risk in Kampala, Uganda. BMC Med 2014;12:122.

30 Michau L, Horn J, Bank A, et al. Prevention of violence against women and girls: lessons from practice. Lancet 2015;385:1672-84.

31 Spencer RA, Shahrouri M, Halasa L, et al. Women's help seeking for intimate partner violence in Jordan. Health Care Women Int 2014;35:380-99.

32 Ikeda A, Kawachi I. Social networks and health. In: Handbook of behavioral medicine. Springer, 2010: 237-61.

33 Shakya HB, Hughes DA, Stafford D, et al. Intimate partner violence norms cluster within households: an observational social network study in rural Honduras. BMC Public Health 2016;16:233.

34 Jewkes R, Flood M, Lang J. From work with men and boys to changes of social norms and reduction of inequities in gender relations: a conceptual shift in prevention of violence against women and girls. Lancet 2015;385:1580-9.

35 Valente TW. Social networks and health: models, methods, and applications. New York: Oxford University Press, 2010.

36 Perry BL, Pescosolido BA, Borgatti SP. Egocentric network analysis: foundations, methods, and models. Cambridge: Cambridge University Press, 2018.

37 Lowe SMP, Moore S. Social networks and female reproductive choices in the developing world: a Systematized review. Reprod Health 2014:11:85.

38 UNICEF. Adolescence: a time that matters, 2002. Available: https:// asksource.info/resources/adolescence-a-time-matters

39 Pescosolido BA, Perry BL, Borgatti SP. Methods for gathering data about alters. egocentric network analysis: foundations, methods, and models. In: Structural analysis in the social sciences. Cambridge: Cambridge University Press, 2018: 109-28.

40 McCarty C, Bernard HR, Killworth PD, et al. Eliciting representative samples of personal networks. Soc Networks 1997;19:303-23.

41 Hogan B, Carrasco JA, Wellman B. Visualizing personal networks: working with participant-aided sociograms. Field methods 2007:19:116-44.

42 Assembly UNG. Declaration on the elimination of violence against women. United nations department of public information, 1997.

43 Watts C, Zimmerman C. Violence against women: global scope and magnitude. Lancet 2002;359:1232-7.

44 Fulu E, Miedema S, Roselli T, et al. Pathways between childhood trauma, intimate partner violence, and harsh parenting: findings from the un Multi-country study on men and violence in Asia and the Pacific. Lancet Glob Health 2017:5:e512-22.

45 Perrin N, Marsh M, Clough A, et al. Social norms and beliefs about gender based violence scale: a measure for use with gender based violence prevention programs in low-resource and humanitarian settings. Confl Health 2019;13:6.
46 Baird S, Hicks J, Jones N. Jordan baseline survey 2017/2018, 2019. Available: https://www.gage.odi.org/publication/jordan-baselinesurvey-2017-18/

47 Burt RS, Meltzer DO, Seid M, et al. What's in a name generator? choosing the right name generators for social network surveys in healthcare quality and safety research. BMJ Qual Saf 2012;21:992-1000.

48 Marin A, Hampton KN. Simplifying the personal network name generator: alternatives to traditional multiple and single name generators. Field methods 2007;19:163-93.

49 Harpham T, Grant E, Thomas E. Measuring social capital within health surveys: key issues. Health Policy Plan 2002;17:106-11.

50 De Silva MJ, Huttly SR, Harpham T, et al. Social capital and mental health: a comparative analysis of four low income countries. Soc Sci Med 2007;64:5-20.

51 Merhi R, Kazarian SS. Validation of the Arabic translation of the multidimensional scale of perceived social support (ArabicMSPSS) in a Lebanese community sample. Arab Journal of Psychiatry 2012;23:159-68 https://search.emarefa.net/en/ detail/BIM-314413-validation-of-the-arabic-translation-of-themultidimensional

52 Dambi JM, Corten L, Chiwaridzo M, et al. A systematic review of the psychometric properties of the cross-cultural translations and adaptations of the multidimensional perceived social support scale (MSPSS). Health Qual Life Outcomes 2018;16:80.

53 Ramaswamy V, Aroian KJ, Templin T. Adaptation and psychometric evaluation of the multidimensional scale of perceived social support for Arab American adolescents. Am J Community Psychol 2009;43:49-56.

54 Kroenke K, Spitzer RL, Williams JBW, et al. An ultra-brief screening scale for anxiety and depression: the PHQ-4. Psychosomatics 2009:50:613-21.

55 Waszak C, Severy LJ, Kafafi L, et al. Fertility behavior and psychological stress: the mediating influence of gender norm beliefs among Egyptian women. Psychol Women Q 2001;25:197-208.

56 Pulerwitz J, Barker G. Measuring attitudes toward gender norms among young men in Brazil development and psychometric evaluation of the GEM scale. Men and Masculinities 2008;10:322-38 https://promundoglobal.org/wp-content/uploads/2014/12/ Measuring-Attitudes-toward-Gender-Norms-among-Young-Menin-Brazil-Development-and-Psychometric-Evaluation-of-the-GEMScale.pdf

57 Wickham H. ggplot2: elegant graphics for data analysis. Springer, 2016.

58 Valente TW. Social network thresholds in the diffusion of innovations. Soc Networks 1996;18:69-89.

59 Berkman LF, Glass T, Brissette I, et al. From social integration to health: Durkheim in the new millennium. Soc Sci Med 2000;51:843-57.

60 Organization WH. Putting women first: ethical and safety recommendations for research on domestic violence against women. Geneva: World Health Organization, 2001.

61 Jacobsen K, Landau LB. Researching refugees: some methodological and ethical considerations in social science and forced migration: UNHCR Geneva, 2003.

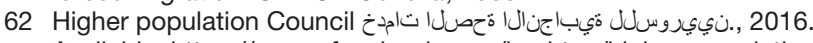
Available: https://ne-np.facebook.com/hashtag/higher_population council?source=feed text\&epa=HASHTAG 